\title{
Large bowel occlusion from fecal impaction: An unusual cause of obstructive cardiogenic shock
}

\author{
Mary Caillat ${ }^{1}$, Olivier Pantet ${ }^{2}$, Tobias Zingg $^{3}$, Zied Ltaief ${ }^{2} \odot$ \\ ${ }^{1}$ The Department of Anesthesia, University Hospital Center \\ Hospitalier Universitaire Vaudois, Lausanne, Switzerland \\ ${ }^{2}$ The Service of Adult Intensive Care Medicine, University Hospital Center \\ Hospitalier Universitaire Vaudois, Lausanne, Switzerland \\ ${ }^{3}$ Department of Visceral Surgery, University Hospital Center \\ Hospitalier Universitaire Vaudois, Lausanne, Switzerland
}

A 69-year-old woman was admitted to the orthopedic department with a femoral shaft fracture requiring osteosynthesis. On the third postoperative day, the patient developed abdominal distension and became progressively tachycardic, hypotensive $(76 / 40 \mathrm{mmHg}$ ) and anuric. Upon arrival in the intensive care unit, hyperlactatemia was noticed $(4.4 \mathrm{mmol} / \mathrm{L})$. Transthoracic echocardiography revealed an extrinsic compression of the left ventricle at the level of the mid-anterolateral wall with a compromise of preload (Fig. 1A), not responding to fluid resuscitation. Computed tomography showed massive fecal impaction extending from the descending colon to the rectum with significant large bowel distension proximally (Fig. 1C), causing a compression of the left ven- tricle (Fig. 1D). During emergent exploratory laparotomy, ischemia of the colon with necrosis of the cecum was found. No anatomic anomaly of the left diaphragm was identified. A right-sided damage-control colectomy was performed, the fecaloma was manually evacuated, and the abdomen was temporarily closed with a negative pressure dressing, resulting in complete resolution of the circulatory shock. The intestinal continuity was re-established 2 days later and the patient fully recovered. Post-operative ultrasound showed normal cardiac cavities (Fig. 1B). Common causes of extra-pericardial tamponade are hematomas, tumors, ascites and hernias. This is a rare case of a trans-diaphragmatic cardiac compression without structural anomaly of the diaphragm.

Conflict of interest: None declared

Address for correspondence: Zied Ltaief, MD, Service of Adult Intensive Care Medicine, Center Hospitalier Universitaire Vaudois, Lausanne 1011, Switzerland, tel: +4179 5566825, e-mail: zied.ltaief@chuv.ch

This article is available in open access under Creative Common Attribution-Non-Commercial-No Derivatives 4.0 International (CC BY-NC-ND 4.0) license, allowing to download articles and share them with others as long as they credit the authors and the publisher, but without permission to change them in any way or use them commercially. 


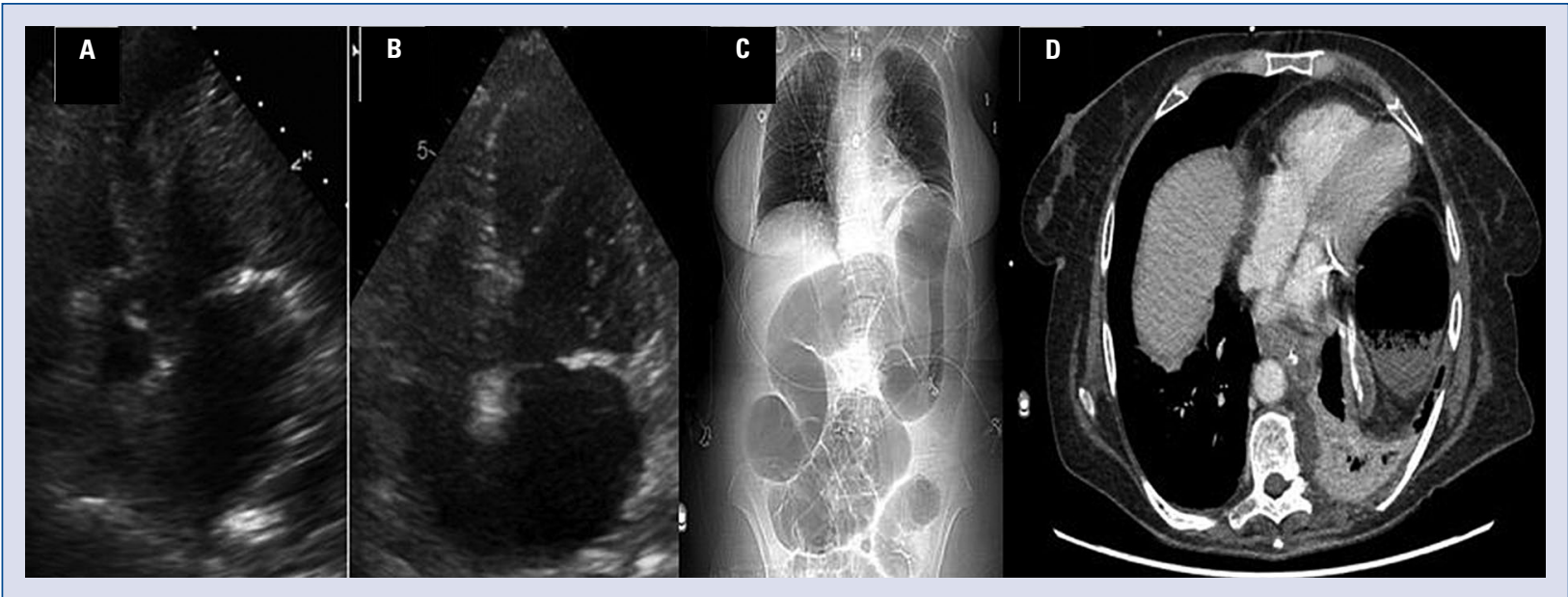

Figure 1. A. Transthoracic apical four chambers echography: extrinsic compression of the left ventricle; B. Transthoracic apical four chambers echography: post-operative normal cardiac cavities; C. Computer tomography, anteroposterior scout; D. Computer tomography, thoracic axial view: dilated large bowel with compression of the left ventricle. 